\title{
Correlation between mast cell density and histological parameters in Helicobacter pylori-associated gastritis
}

\author{
Mana Taweevisit, Naruemon Klaikaew \\ Department of Pathology, Faculty of Medicine, Chulalongkorn University, Bangkok 10330, Thailand
}

\begin{abstract}
Background: Helicobacter pylori (H. pylori) are a major cause of chronic gastritis and peptic ulcer. This organism plays a role in gastric carcinoma and B-cell lymphoma. However, the exact pathogenesis of gastric inflammation is still unclear. Mast cells, the important inflammatory cells for allergic process, may participate in the pathogenesis of gastritis related to $\mathrm{H}$. pylori infection.

Objective: Analyze the relationship between mast cell density, H. pylori intensity, histological alterations, and their severity of biopsy proven gastritis.

Methods: One hundred eleven biopsied specimens were collected from Thai patients who were diagnosed H. pylori-associated gastritis of the antrum at King Chulalongkorn Memorial Hospital between 2002 and 2005. All biopsied specimens were examined according to the Updated Sydney System. Mast cell density was evaluated by $0.1 \%$ toluidine-stained sections.

Results: The higher mast cell density was correlated with increased neutrophilic infiltration $(r=0.220, p=0.020)$, chronic inflammatory cell infiltration $(r=0.381, p<0.001)$, and lymphoid aggregation $(r=0.271, p=0.004)$. No relationship was found between mast cell density and intensity of $\mathrm{H}$. pylori, glandular atrophy, or intestinal metaplasia.
\end{abstract}

Conclusion: Mast cells might take part in the pathogenesis of H. pylori gastritis.

Keywords: Chronic gastritis, Helicobacter pylori, mast cell

Helicobacter pylori (H. pylori) organisms are spiral-shaped gram-negative microaerophilic bacteria and potent producers of the enzyme urease. They are highly motile because of multiple unipolar flagella, inhabiting various areas of the stomach and duodenum. These bacteria are prevalent in more than half of the world's population and accepted to be the significant cause of chronic infection of the human stomach. In general, the prevalence of $\mathrm{H}$. pylori infection is increasing with age and higher in developing countries including Thailand [1,2].

The normal gastric mucosa contains very few white blood cells in the lamina propria [3]. In chronic active $\mathrm{H}$. pylori gastritis, the bacteria enhance gastric mucosal infiltration with neutrophils, eosinophils,

Correspondence to: Mana Taweevisit, MD, Department of Pathology, Faculty of Medicine, Chulalongkorn University, 1873, Rama IV, Pathumwan, Bangkok 10330, Thailand. E-mail:dr.mana4@gmail.com lymphocytes, plasma cells, and macrophages leading to tissue damage from reactive oxygen species [4]. Without any treatment, glandular cell loss and intestinal metaplasia occur [3]. According to patient approach, the disease may remain clinically silent or progress to peptic ulcer, and carries an increased risk of gastric adenocarcinoma and primary gastric B-cell lymphoma [4]. Although many diseases have been associated with $\mathrm{H}$. pylori, the mechanism of chronic active inflammation of the gastric mucosa has not been completely explained.

Mast cells are tissue-dwelling inflammatory cells found principally near blood vessels and along mucosa including gastrointestinal tract [5]. They are possibly one of the first inflammatory cells to make contact with organisms and produce pro-inflammatory cytokines, protease enzymes and inflammatory mediators after activation [6]. In H. pylori gastritis, mast cell density increases markedly in the affected gastric mucosa compared with that in $\mathrm{H}$. pylori- 
negative gastritis, either corpus or antrum. In addition, the amount of mast cells reduces significantly after bacterial eradication [7, 8]. These indicate a possible role of mast cells in maintenance gastritis and reparation of damaging gastric mucosal tissue. Nalajima et al. [9] reported a significant relationship between mast cell density and $\mathrm{H}$. pylori intensity. However, their data were not enough to obtain the definite conclusion whether direct $\mathrm{H}$. pylori effect or the inflammation secondary to $\mathrm{H}$. pylori affecting density of mast cells.

In this study, we investigated the relationship between mast cell density, histopathological scores of gastritis, and presence of $\mathrm{H}$. pylori in the antral mucosa. This may provide a clue to establish a new concept of the role of mast cells in the pathogenesis of $\mathrm{H}$. pyloriassociated gastritis.

\section{Materials and methods}

This study was approved by the Ethics Committee of Faculty of Medicine, Chulalongkorn University.

Gastric antral biopsies from $111 \mathrm{H}$. pyloriassociated gastritis in Thai patient were retrieved from the surgical pathology file at King Chulalongkorn Memorial Hospital between 2002 and 2005. The tissue sections were reviewed on the hematoxyline and eosin and giemsa-stained tissue sections. The $\mathrm{H}$. pylori density, severity and activity of gastritis, glandular atrophy and intestinal metaplasia were investigated using a visual analog scale according to the Updated Sydney System [3]. The intensity of H. pylori, infiltration of gastric mucosa by polymorphonuclear leukocytes and mononuclear cells, gland atrophy and intestinal metaplasia were divided into none or mild, moderate, and marked level. In addition, the gastric mucosal lymphoid aggregates were identified and scored, and defined by accumulations of lymphocytes and plasma cells with or without germinal centers as previously described by Chen et al. [10]. All gastric antral specimens were evaluated and scored independently by two pathologists. Disagreements were resolved by consensus.

For mast cell density determination, the epithelial and submucosal mast cells were stained with $0.1 \%$ toluidine blue. The slides were scanned to identify the cells with intracytoplasmic metachromatic granules and counted. For each case, the four areas of highest mast cell density were selected by microscopic examination of the slides, and photographed under a Nikon Microscope Eclipse E600W microscope equipped with Nikon Digital Camera and DXM1200F software (Nikon, Tokyo, Japan). Mast cells along gastric mucosa were counted manually in each of the four fields. The results were combined to arrive at a count for mast cells $/ \mathrm{mm}^{2}$.

\section{Statistical analysis}

The data were analyzed in terms of the Spearman's rank correlation coefficient, using SPSS for Windows, Version 11.5. Confidence intervals were 95\%. A p-value of $<0.05$ was considered statistically significant.

\section{Results}

The 111 cases consisted of 59 males (53\%) and 52 females (47\%) with a mean age of 43 years. The relationships between mast cell density and histological parameters of the gastric antrum were shown in Table 1.

Table 1. The mean of mast cell density related to several values in various degrees.

\begin{tabular}{llllll}
\hline $\begin{array}{l}\text { Mean of mast cells/mm } \\
\text { (SD) }\end{array}$ & $\begin{array}{l}\text { None or Mild } \\
\text { Number (\%) }\end{array}$ & $\begin{array}{l}\text { Moderate } \\
\text { Number (\%) }\end{array}$ & $\begin{array}{l}\text { Marked } \\
\text { Number (\%) }\end{array}$ & $\begin{array}{l}\text { Correlation } \\
\text { coefficient (r) }\end{array}$ & P-value \\
\hline H. pylori & $13(12.4)$ & $18(13.5)$ & $13(12.2)$ & 0.030 & 0.751 \\
Polymorphs & $11(11.1)$ & $15(13.4)$ & $18(13.7)$ & 0.220 & $0.020^{*}$ \\
Mononuclear cells & $8(7.4)$ & $12(12.2)$ & $19(13.3)$ & 0.381 & $<0.001^{*}$ \\
Lymphoid aggregation & $12(11.3)$ & $20(15.5)$ & $23(16.3)$ & 0.271 & $0.004^{*}$ \\
Glandular atrophy & $14(12.0)$ & $15(13.5)$ & $13(11.19)$ & 0.032 & 0.735 \\
Intestinal metaplasia & $13(12.5)$ & $20(12.6)$ & $24(15.6)$ & 0.167 & 0.080 \\
\hline
\end{tabular}


Figure 1 shows images demonstrating mast cells in gastric mucosa with mild gastritis and severe gastritis. The mast cell density in both $\mathbf{A}$ and $\mathbf{B}$ was significantly correlated with gastric mucosal inflammatory response where the higher quantity of mast cells, the higher score of neutrophils $(r=0.220$, $p=0.020)$, chronic inflammatory cell infiltrations $(r=0.381, p<0.001)$, and mucosal lymphoid aggregations $(r=0.271, p=0.004)$. Although the mast cell density tended to increase in association with increasing score of intestinal metaplasia, but no relationship was found $(r=0.167, p=0.080)$. For intensity of $\mathrm{H}$. pylori and glandular atrophy, no significant correlation were observed with mast cell density $(r=0.030, p=0.751$ and $r=0.032, p=0.735$, respectively).

\section{Discussion}

H. pylori organisms are the major causative bacteria leading to chronic infection of the stomach. The prevalence is associated with socio-economic status and patients' age rather than race [2]. In Thailand, the prevalence of $\mathrm{H}$. pylori is as high as 74\% [11]. The initial pathogenesis of H. pylori gastritis is enhancement of both cellular and humoral immune systems via the antigenic stimulus of mucosal monocytes and T-lymphocytes after epithelial attachment by organisms. Various sorts of inflammatory cells are recruited. Subsequently release cytokines, proteases, prostaglandins, and reactive oxygen metabolites are released resulting in gastric mucosal destruction followed with glandular atrophy and intestinal metaplastic change $[12,13]$.

Besides allergic stimuli, mast cells are the major type of leukocytes, involving in both acute and late phase responses to eradicate most organisms $[6,14]$. According to Nakajima et al. [8], mast cells cooperate in the process of gastritis, associated with the development of peptic ulcers [8]. Their finding provides interesting information on how mast cells modulate gastritis.

\section{A}

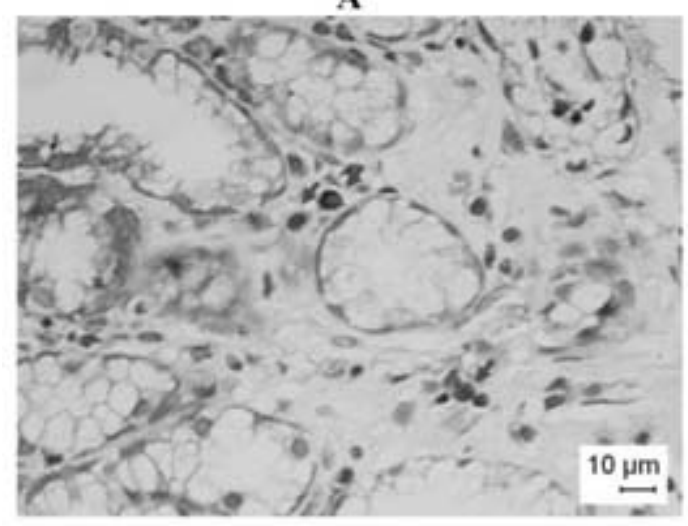

B

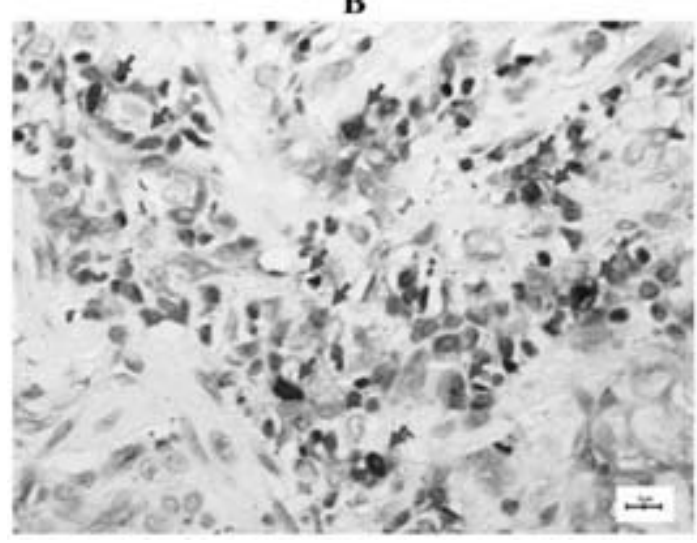

Fig. 1 A: Minimal amounts of mast cells in gastric mucosa with mild gastritis. B: high mast cell density in severe gastritis. They are stained by Toluidine blue and demonstrated by cells with metachromatic stain (indicated by arrows). (Original magnification x 600). 
In this study, the density of mast cells in $\mathrm{H}$. pylori gastritis was observed to increase significantly in patients with higher degree of neutrophilic infiltration. Previous reports $[5,15]$ revealed that during initial gastric infection with $\mathrm{H}$. pylori, mast cells degranulate several necessary cytokines for inflammatory cell accumulation. In supernatants cultured from H. pyloripositive subjects, the amount of tumor necrotic factor (TNF)- $\alpha$, interleukin (IL)-6, and IL-8 increased markedly, all of those are certainly secreted by mast cells [16-18]. Both TNF- $\alpha$ and IL-6 are related to the degree of severity and activity of gastric inflammation [16]. It is notable that mast cells are the major effecter cells that release TNF- $\alpha$ via both $d e$ novo synthesis and storage in their granules before activation [6]. Mast cells also secrete tryptase, chymase, and platelet-activating factor that play a crucial role in chemotactic activity for neutrophils [5, $9,14]$. In addition, the preformed mast cell tryptase can activate IL-6 and IL-8 production and release in human eosinophils. The leukocytes frequently infiltrate gastric mucosa, which is infected with $\mathrm{H}$. pylori $[3,19]$.

Mast cell density was associated with mononuclear cell infiltration and lymphoid aggregation in our study. In fact, lymphocytes and macrophages themselves can produce chemotactic factors for mast cells in human [8]. On the other hand, mast cells also secrete chymase enzyme for accumulation of macrophages and $\mathrm{T}$ lymphocytes [14]. The presence of lymphoid aggregates with or without follicles in gastric mucosa is a conspicuous pathological feature of H. pylori-associated chronic gastritis [3]. To create this mucosal response, the organisms activate specific immunological reaction by themselves and cytotoxin via certain cytokines including IL-2 and IL-6, allowing proliferation of $B$ and $T$ lymphocytes and macrophages together with development of lymphoid follicle formation [19]. In animal model, mucosal intestinal mast cells number is obviously increased in the number after IL-2 induction [20].

Our study showed no significant correlation between the density of mast cells and intensity of $\mathrm{H}$. pylori. This result was discordant with the prior study from Turkish population [9]. For this reason, increase in mast cell density could not be explained from direct effect of $\mathrm{H}$. pylori intensity alone, but increasing mast cells may be a secondary change due to inflammatory response. The other possibility is geographical differences between molecular epidemiology and clinical manifestation of $\mathrm{H}$. pylori infections [21-23]. Thailand is the area of outstanding $\mathrm{H}$. pylori genotypic change [1].

In conclusion, mast cell density was high in $\mathrm{H}$. pylori gastritis with greater neutrophilic and mononuclear cell infiltration, and lymphoid aggregation. No significant correlation was found between mast cell density and intensity of $\mathrm{H}$. pylori, and degree of glandular atrophy and intestinal metaplasia. This current observation done in Thai population was consistent with previous studies, indicating that mast cells may be necessary in pathogenesis of gastritis caused by $\mathrm{H}$. pylori infection.

The author has no conflict of interest to report.

\section{References}

1. Vilaichone RK, Mahachai V, Tumwasorn S, Wu JY, Graham DY, Yamaoka Y. Molecular epidemiology and outcome of Helicobacter pylori infection in Thailand: a cultural cross roads. Helicobacter. 2004; 9:453-9.

2. Zheng PY, Hua J, Yeoh KG, Ho B. Association of peptic ulcer with increased expression of Lewis antigens but not cagA, iceA, and vacA in Helicobacter pylori isolates in an Asian population. Gut. 2000; 47:18-22.

3. Dixon MF, Genta RM, Yardley JH, Correa P. Classification and grading of gastritis. The updated Sydney System. International Workshop on the Histopathology of Gastritis, Houston 1994. Am J Surg Pathol. 1996; 20:1161-81.

4. McGee DJ, Mobley HL. Pathogenesis of Helicobacter pylori infection. Curr Opin Gastroenterol. 2000; 16: 24-31.

5. Basso D, Navaglia F, Brigato L, Di Mario F, Rugge M, Plebani M. Helicobacter pylori non-cytotoxic genotype enhances mucosal gastrin and mast cell tryptase. J Clin Pathol. 1999; 52:210-4.

6. Munoz S, Hernandez-Pando R, Abraham SN, Enciso JA. Mast cell activation by Mycobacterium tuberculosis: mediator release and role of CD48. J Immunol. 2003; 70:5590-6.

7. Mysorekar VV, Dandekar CP, Prakash BS. Mast cells in Helicobacter pylori associated antral gastritis. Indian J Pathol Microbiol. 2003; 46:605-9.

8. Nakajima S, Bamba N, Hattori T. Histological aspects and role of mast cells in Helicobacter pylori-infected gastritis. Aliment Pharmacol Ther. 2004; 20 Suppl 1: 165-70.

9. Kayaselcuk F, Serin E, Gumurdulu Y, Bircan S, Tuncer I. Relationship between gastritis severity, Helicobacter pylori intensity and mast cell density in the antrum 
and corpus. Turk J Gastroenterol. 2002; 13:154-8.

10. Chen XY, Liu WZ, Shi Y, Zhang DZ, Xiao SD, Tytgat GN. Helicobacter pylori associated gastric diseases and lymphoid tissue hyperplasia in gastric antral mucosa. J Clin Pathol. 2002; 55:133-7.

11. Vivatvakin B, Theamboonlers A, Semakachorn N, Wongsawadi L. Prevalence of CagA and VacA genotype of Helicobacter pylori in Thai children. J Med Assoc Thai. 2004; 87:1327-31.

12. Velin D, Michetti P. Immunology of Helicobacter pylori infection. Digestion. 2006; 73:116-23.

13. Matsuhisa TM, Yamada NY, Kato SK, Matsukura NM. Helicobacter pylori infection, mucosal atrophy and intestinal metaplasia in Asian populations: a comparative study in age-, gender- and endoscopic diagnosis-matched subjects. Helicobacter. 2003; 8: 29-35.

14. Matsuo T, Ikura Y, Ohsawa M, Ogami M, Kayo S, Yoshimi N, et al. Mast cell chymase expression in Helicobacter pylori-associated gastritis. Histopathology. 2003; 43:538-49.

15. Saperas E. The role of mast cells in gastrointestinal inflammation. Gastroenterology. 1996; 110:1656-8.

16. Bodger K, Bromelow K, Wyatt JI, Heatley RV. Interleukin 10 in Helicobacter pylori associated gastritis: immunohistochemical localisation and in vitro effects on cytokine secretion. J Clin Pathol. 2001; 54:285-92.

17. Kempuraj D, Huang M, Kandere-Grzybowska K, Basu S, Boucher W, Letourneau R, et al. Azelastine inhibits secretion of IL-6, TNF-alpha and IL-8 as well as NFkappaB activation and intracellular calcium ion levels in normal human mast cells. Int Arch Allergy Immunol. 2003; 132:231-9.

18. Theoharides TC, Bielory L. Mast cells and mast cell mediators as targets of dietary supplements. Ann Allergy Asthma Immunol. 2004; 93:S24-34.

19. Temkin V, Kantor B, Weg V, Hartman ML, Levi-Schaffer F. Tryptase activates the mitogen-activated protein kinase/activator protein-1 pathway in human peripheral blood eosinophils, causing cytokine production and release. J Immunol. 2002; 169:2662-9.

20. Sasaki Y, Yoshimoto T, Maruyama H, Tegoshi T, Ohta N, Arizono N, Nakanishi K. IL-18 with IL-2 protects against Strongyloides venezuelensis infection by activating mucosal mast cell-dependent type 2 innate immunity. J Exp Med. 2005; 202:607-16.

21. Erzin Y, Altun S, Dobrucali A, Aslan M, Erdamar S, Dirican A, et al. Analysis of serum antibody profile against $\mathrm{H}$ pylori VacA and CagA antigens in Turkish patients with duodenal ulcer. World J Gastroenterol. 2006; 12:6869-73.

22. Liu Y, Ponsioen CI, Xiao SD, Tytgat GN, Ten Kate FJ. Geographic pathology of Helicobacter pylori gastritis. Helicobacter. 2005; 10:107-13.

23. Lin HJ, Perng CL, Lo WC, Wu CW, Tseng GY, Li AF, et al. Helicobacter pylori cagA, iceA and vacA genotypes in patients with gastric cancer in Taiwan. World J Gastroenterol. 2004; 10:2493-7. 